\title{
Glecaprevir and Pibrentasvir Combination Antiviral Therapy for Hemodialysis Patients Infected with the Hepatitis C Virus
}

\author{
M Zubkin ${ }^{1 *}$, 0 Balkarova ${ }^{2}$, P Bogomolov ${ }^{3}$, R Golbraikh ${ }^{4}$, I Kim ${ }^{1}$, R Nuriakhmetov ${ }^{5}$, E Strebkova ${ }^{6}$, V Chervinko ${ }^{1}$, G \\ Schepetkova ${ }^{1}$ and E Kryukov ${ }^{1}$
}

${ }^{1}$ GN Gabrichevsky Research Institute for Epidemiology and Microbiology, Russia

${ }^{2}$ City Hospital No. 24, Russia

${ }^{3}$ MF Vladimirsky Moscow Regional Research Clinical Institute, Russia

${ }^{4}$ Perm Krai Clinical Infectious Hospital, Russia

${ }^{5}$ Kuvatov Republican Clinical Hospital, Russia

${ }^{6}$ Samara State Medical University, Russia

Submission: December 06, 2019; Published: January 07, 2020

*Corresponding author: Mikhail Zubkin, Chief of Clinical and Diagnostic Department, G.N. Gabrichevsky Research Institute for Epidemiology and Microbiology, 10 Admiral Makarov Street, 125212, Moscow, Russia

\section{Abstract}

Background and Aims: The population of patients on hemodialysis (HD) is considered one of the most accessible for the implementation of the WHO HCV Infection Eradication Program. Until recently the main obstacle to its elimination was the lack of antiviral drugs for the treatment of HCV genotypes 2 and 3 in patients with a low glomerular filtration rate. The new combination of Glekaprevir/Pibrentasvir opens up additional opportunities to achieve this goal. The aim of the study was to assess the efficacy and safety of this therapy in patients with stage 5 chronic kidney disease receiving HD.

Methods: 16 HD patients with HCV genotypes 2 (one with the recombinant 2k/1b subtype) and 3 were treated with GLE/PIB for 8 or 12 weeks depending on the degree of fibrosis.

Results: A sustained virological response at 12 and 24 weeks was achieved in all patients with a minimum number of adverse events. In 13 of 14 patients, positive changes to transient liver elastography parameters were detected after completion of the antiviral therapy. However, this could be associated with a decrease in the inflammatory activity of the disease rather than with the decreased severity of hepatic fibrosis.

Conclusion: HCV infection treatment with GLE/PIB in hemodialysis patients is effective and safe.

Keywords: Hepatitis C Virus; Hemodialysis; Patients; Glecaprevir; Pibrentasvir

Abbreviations: HCV: Hepatitis C Virus; ESKD: End-Stage Kidney Disease; CHC: Chronic Hepatitis C; SVR: Sustained Virological Response; TE: Transient Elastography; F: Fibrosis Stages; GLE/PIB: Glecaprevir/Pibrentasvir

\section{Introduction}

Hemodialysis patients are at a high risk of hepatitis $C$ virus (HCV) infection. It is well known that chronic HCV infection is responsible not only for the so-called "hepatic" manifestations (chronic hepatitis, which may be complicated by liver cirrhosis and hepatocellular carcinoma), but also for the "extrahepatic" manifestations. The most frequent extrahepatic manifestation is mixed cryoglobulinemia. Mixed cryoglobulinemia can lead to cryoglobulinemic vasculitis and even non-Hodgkin B-cell lymphoma. Other types of "extrahepatic" chronic HCV infection manifestations affecting various organs (kidneys, thyroid gland, joints) and even cardiovascular and central nervous systems have been reported [1,2].

In patients with end-stage kidney disease (ESKD) undergoing $\mathrm{HD}$, chronic hepatitis $\mathrm{C}(\mathrm{CHC})$ progression is less severe compared to patients with a normal renal function, while the development of "extrahepatic" manifestations is not common [3-5]. However, 
the prognosis for HCV-infected HD patients is worse than for non-infected patients. The course of chronic HCV infection is particularly unfavorable in patients after kidney transplantation, since the "hepatic" complication rate significantly increases with a concomitant immunosuppressive therapy background. In contrast to HD patients, renal transplant recipients have significantly higher odds of developing "extrahepatic" HCV infection manifestations, in particular those associated with renal transplant diseases [6], which leads to reduced graft survival $[6,7]$.

So, the problem of chronic HCV infection treatment has always been a challenging issue for patients receiving renal replacement therapy (RRT). Until recently, i.e. before the introduction in clinical practice of direct antiviral agents (DAAs), this group of patients was historically difficult to treat. Interferon therapy, on which chronic hepatitis C treatment was based, characterized by poor tolerability in HD patients compared to patients with intact renal function and the limited use of ribavirin due to ESKDrelated anemia. The interferon-based therapy in renal transplant recipients was contraindicated due to the high risk of graft loss as a result of irreversible rejection [8].

The introduction in clinical practice of DAAs leads to chronic HCV infection treatment with a high efficacy and favorable safety profile, even in the population of HD patients. In several publications it was reported that the sustained virological response (SVR) rate 12 weeks after the end of antiviral therapy approached $100 \%$ in HD patients [9-11]. However, the affected population included only patients with HCV 1 or 4 genotypes. Furthermore, the treatment results were not affected by liver cirrhosis or the lack of response to previous interferon therapy [12].

With mandatory HCV infection monitoring in hemodialysis centers in combination with highly effective modern antiviral therapy we can discuss the possibility of the complete elimination of this infection in the dialysis population. This goal was hampered by restrictions for Sofosbuvir-based DAA regimens in patients with a low glomerular filtration rate $(<30 \mathrm{ml} / \mathrm{min})$, which had no alternative treatment for HCV infection 2 and 3 genotypes. Recently, a pangenotypic combination of NS3/NS4A and NS5A inhibitors, Glecaprevir/Pibrentasvir (GLE/PIB) has been registered. Although it is acceptable for patients on HD, experience with it is still limited to use primarily in Japan.

The aim of this article is to demonstrate the efficacy and safety of GLE/PIB for the treatment of HD patients with HCV infection 2 and 3 genotypes in our local practice.

\section{Patients and Methods}

An open prospective study was conducted in 4 Russian HD centers. 16 HCV-infected patients who received HD-therapy were followed up from November 2016 to July 2018. The most common cause of ESRD in those patients was chronic glomerulonephritis. The mean age of the patients was $48.8 \pm 11.5$ years. The majority of the patients were male $(n=11) .62 .5 \%$ of the patients were infected before HD treatment was initiated. The duration of hemodialysis treatment when the DAA therapy was initiated was $100.9 \pm 70.1$ months. The duration of HCV infection from the moment of its diagnosis was $121.9 \pm 57.4$ months. No patients enrolled in the study had previously received antiviral therapy. The exclusion criteria included HBV/HIV co-infection, decompensated liver cirrhosis (Child-Pugh class B and C) and hepatocellular carcinoma. All the patients received recombinant erythropoetin treatment to compensate nephrogenic anemia.

The CHC activity was determined by measuring the increase in the blood liver enzyme level. A low activity (ALT $\leq 100 \mathrm{U} / \mathrm{l}$ ) was observed in $14(87.5 \%)$ patients, while a moderate (ALT $>100$ $\mathrm{U} / \mathrm{l})$ activity was observed only in $2(12.5 \%)$ patients. The viral load in the studied group reached $6.1 \times 105(1.6 \times 104 ; 1.0 \times 106) \mathrm{IU} /$ $\mathrm{ml}$ (Table 1). However, a high level of viremia $(>8.0 \times 105 \mathrm{IU} / \mathrm{ml})$ was detected only in $31.3 \%$ of patients. Among the patients, HCV genotype 3 was the most abundant (75\%). Most of the patients already had signs of liver fibrosis at the start of treatment, and half of these patients had moderate or severe fibrosis, while $25 \%$ had liver cirrhosis.

Table 1: Parameters of activity and the $\mathrm{CHC}$ stage.

\begin{tabular}{|c|c|c|c|c|}
\hline Viral Load, IU/ml & $<4 \times 10^{5}$ & $4-8 \times 10^{5}$ & $>8 \times 10^{5}$ & Median $6.1 \times 10^{5}\left(1.6 \times 10^{4} ; 1.0 \times 10^{6}\right)$ \\
\hline Number of patients, $\mathrm{n}$ & 6 & 5 & 5 & 16 \\
\hline HCV genotype & $1,4,5,6$ & 2 & $2 \mathrm{k} / 1 \mathrm{~b}$ & 3 \\
\hline Number of patients, $\mathrm{n}$ & - & 3 & 1 & 12 \\
\hline $\begin{array}{c}\text { Fibrosis stage according to the METAVIR } \\
\text { Score System }\end{array}$ & $\mathrm{F} 0-\mathrm{F} 1(<7 \mathrm{kPa})$ & $\begin{array}{l}\text { F1-F2; F2 (7-9.5 } \\
\text { kPa) }\end{array}$ & $\begin{array}{l}\text { F2-F3; F3 (9.6- } \\
12.5 \mathrm{kPa})\end{array}$ & F3-F4; F4 (>12.6 kPa) \\
\hline Number of patients, $\mathrm{n}$ & 4 & 2 & 6 & 4 \\
\hline
\end{tabular}




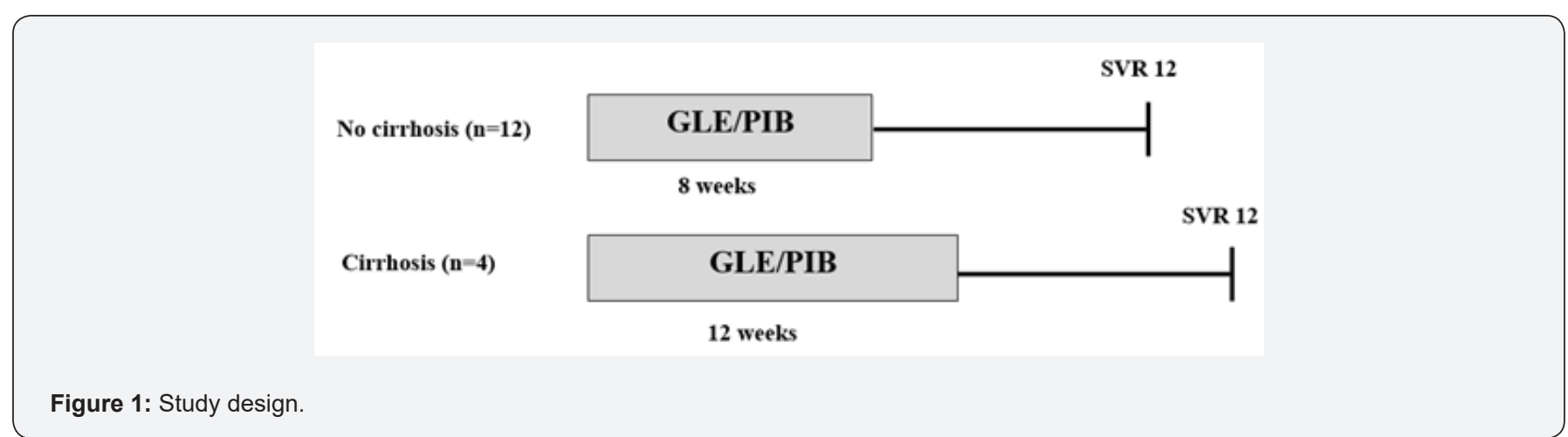

All patients were treated with following antiviral therapy: GLE/PIB 300/120 mg QD (see Figure 1 for the study design). The duration of the treatment depended on the fibrosis stage. The treatment efficacy was assessed based on the absence of viremia 12 and 24 weeks after its completion (SVR12/SVR24) and changes to clinical hepatitis activity and liver fibrosis severity. Blood samples were collected at each study visit before dialysis, and plasma HCV RNA levels were quantified using Cobas TaqMan realtime PCR. The viremia level was assessed during the treatment at 4,8 , and 12 weeks and 12 and 24 weeks after termination of the treatment (sensitivity: 5-15 IU/ml). In cases with HCV genotype 2 a deep sequencing was performed - and the chimeric $2 \mathrm{k} / 1 \mathrm{~b}$ variant was diagnosed in 1 patient. The degree of liver fibrosis was evaluated by the results of transient elastography (TE) obtained with the Tuch 506 FibroScan. The fibrosis stages (F) were graded according to the manufacturer's recommendations [13].

\section{Statistics}

Continuous variables are presented as mean/median values. Categorical variables are presented as numbers and percentages. Comparisons between categorical variables were performed by the Chi-square test as appropriate. Continuous variables were compared by the T-test or non-parametric tests. The $\mathrm{p}$ value $<0.05$ was considered significant. A statistical analysis was performed using SPSS v.22 statistical software.

\section{Results}

Most of the patients in the study group had a significant viral load $\left(>4.0 \times 10^{5} \mathrm{IU} / \mathrm{ml}\right)$. The minimum plasma HCV RNA level was $4.4 \times 10^{3} \mathrm{IU} / \mathrm{ml}$. Four weeks after administration of GLE/PIB, the virus was eliminated in 15 of 16 patients. Only one patient with liver cirrhosis had a detectable level of HCV RNA at week 4, with a reduction in the viral load by more than $10^{3} \mathrm{IU} / \mathrm{ml}$. In this patient the HCV was eliminated at week 8. All patients achieved SVR12 and SVR24. Before the start of treatment, slightly increased ALT, gamma-glutamyltranspeptidase (GGT), and alkaline phosphatase (AP) activity was observed in the patient's group (Table 2A). A higher than normal ALT level was detected in 9 of 16 patients (Table 2B). Upon completion of the treatment, liver enzyme activity returned to normal, and it was still 1.5 times over the upper normal limit. Before the start of treatment, signs of liver fibrosis of varying severity were determined in 12 of 16 patients. The mean liver stiffness was $12.3 \pm 7.7 \mathrm{kPa}$. A correlation between fibrosis severity and the duration of chronic hepatitis $C$, viral load level, and clinical disease activity could not be established $(\mathrm{p}<0.3$, $\mathrm{p}<0.6$, and $\mathrm{p}<0.9$, respectively).

Table 2A \& B: Changes to clinical parameters and liver fibrosis stages as a result of antiviral therapy.

\begin{tabular}{|c|c|c|c|}
\hline \multicolumn{3}{|c|}{ Biochemistry Parameters } & After Therapy \\
\hline & Before Therapy & $12.5 \pm 7.0$ & 0.86 \\
\hline Total bilirubin, $\mu$ mol/l & $13.5 \pm 5.4$ & $15.9 \pm 7.1$ & $<0.01$ \\
\hline ALT, U/l & $58.2 \pm 51.9$ & $22.0 \pm 9.3$ & $<0.03$ \\
\hline AST, U/l & $39.5 \pm 32.2$ & $36.4 \pm 24.5$ & $<0.04$ \\
\hline GGT, U/l & $50.9 \pm 32.1$ & $108.0 \pm 50.9$ & $<0.05$ \\
\hline AP, U/l & $194.1 \pm 174.5$ & & $<0.01$ \\
\hline
\end{tabular}




\begin{tabular}{|c|c|c|c|c|c|c|}
\hline \multirow{3}{*}{ Pts } & \multicolumn{6}{|c|}{ ALT and Liver Fibrosis Stage in Each Patient } \\
\hline & \multicolumn{2}{|c|}{ ALT, U/l } & \multicolumn{2}{|c|}{ Liver Stiffness, kPa } & \multicolumn{2}{|c|}{ Fibrosis Stages } \\
\hline & Before Therapy & After Therapy & Before Therapy & After Therapy & Before Therapy & After Therapy \\
\hline 1 & 62 & 25 & 11.8 & 6.3 & F3 & F0-F1 \\
\hline 2 & 201 & 8 & 9.5 & 6.8 & F3 & F0-F1 \\
\hline 3 & 62 & 6 & 11.8 & 6.4 & F3 & F0-F1 \\
\hline 4 & 61 & 9 & 10.1 & 7.2 & F3 & F1-F2 \\
\hline 5 & 158 & 18 & 20.9 & 11.7 & $\mathrm{~F} 4$ & F3 \\
\hline 6 & 31 & 19 & 10.2 & 9.4 & F3 & F2-F3 \\
\hline 7 & 20 & 10 & 8.9 & 6.8 & $\mathrm{~F} 1-\mathrm{F} 2$ & $\mathrm{~F} 0-\mathrm{F} 1$ \\
\hline 8 & 58 & 39 & 11.6 & 10.2 & F3 & F3 \\
\hline 9 & 52 & 27 & 24.6 & 27 & F4 & $\mathrm{F} 4$ \\
\hline 10 & 15 & 15 & 30.7 & 16.8 & $\mathrm{~F} 4$ & $\mathrm{~F} 4$ \\
\hline 11 & 26 & 10 & 6.5 & 4.3 & F0-F1 & F0-F1 \\
\hline 12 & 21 & 12 & 5.7 & 5.4 & F0-F1 & F0-F1 \\
\hline 13 & 77 & 57 & 5.1 & 4.4 & $\mathrm{~F} 0-\mathrm{F} 1$ & F0-F1 \\
\hline 14 & 19 & 7 & 4.9 & 4.5 & F0-F1 & F0-F1 \\
\hline 15 & 21 & 15 & 16 & - & $\mathrm{F} 4$ & - \\
\hline 16 & 47 & 8.6 & 8.8 & - & F2 & - \\
\hline
\end{tabular}

The follow up after the therapy lasted from 24 to 72 weeks. Repeated elastography was performed in 14 of 16 patients. In this period, the index characterizing liver tissue stiffness significantly improved, dropping to $9.1 \pm 6.2 \mathrm{kPa}$ (Table 2A). An improvement in the TE value was observed in 13 of 14 patients. Furthermore, in seven patients the fibrosis stage changed (Table 2B). This improvement was more marked in patients with F3. In three cases, its stiffness decreased to F0-F1 according to the METAVIR Score System. The fibrosis stages in two other patients dropped to F1-F2 and F2-F3, respectively, and in one patient F4 fibrosis transformed into F3. There was yet another positive case demonstrating the transformation of the F1-F2 fibrosis stage into F0-F1. The stage did not change during therapy only in three patients with advanced fibrosis (two with F4 and one with F3). In one more patient with F4 fibrosis, elastography parameters slightly worsened during the observation period. This patient had CHC and autosomal dominant polycystic kidney disease with liver involvement, and the TE results could not be considered reliable due to severe cystic lesions. Four other patients remained at the
F0-F1 fibrosis stage.

To evaluate the impact of inflammation activity on TE results, we analyzed the relationship between ALT level changes and the degree of improvement of liver stiffness after the DAAs. At the same time, A fibrosis stage decrease by 1 or more grades was considered as significant (Figure 2). It turned out that ALT activity was initially high in all five patients with significant improvments in elastography parameters, whereas in the absence of such changes, the baseline ALT level increased only in 3 of 9 patients $(\mathrm{p}<0.02)$. This suggests that the TE improvement after the DAAs may be related to decreased inflammatory activity as a result of the elimination of the virus. The GLE/PIB combination was safe in HD patients. No serious adverse events were observed in the study group. Only $25 \%$ patients had moderate pruritus. Hemoglobin levels remained stable during the treatment, and an erythropoietin dose increase was not required. No cases of antiviral therapy interruption or premature termination were registered. 


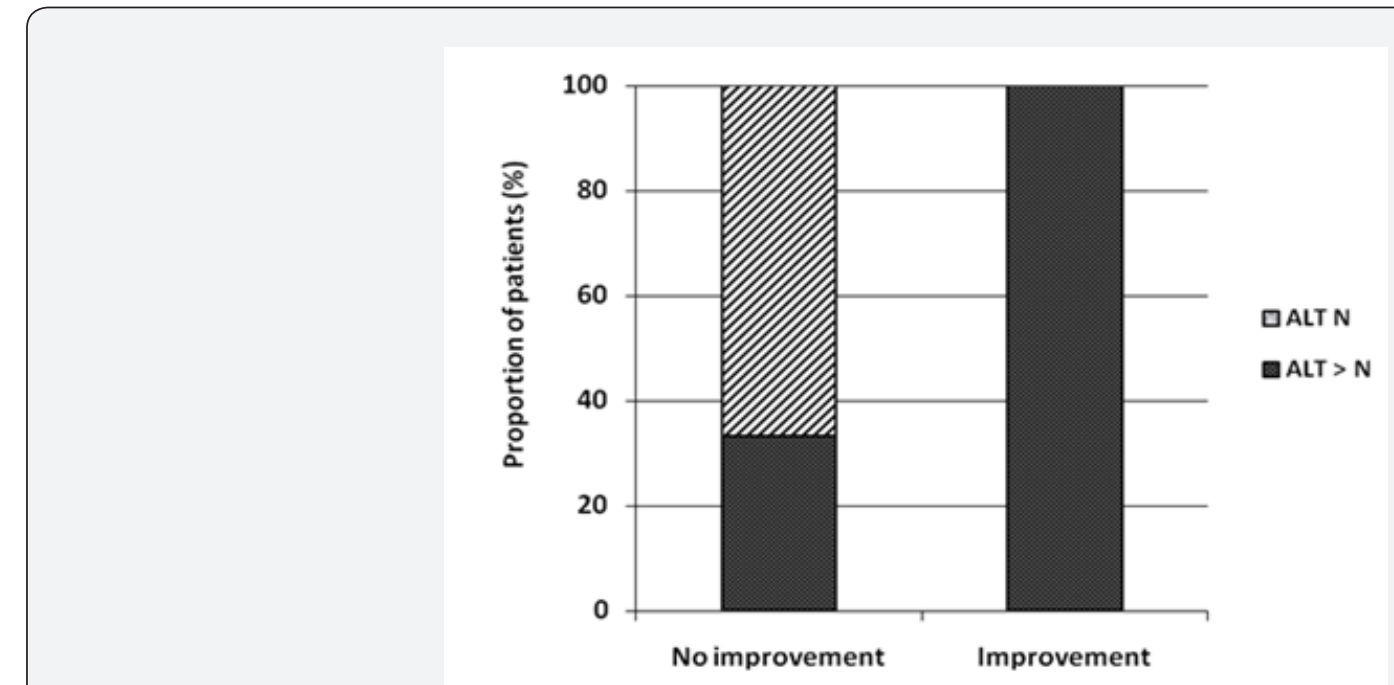

Figure 2: Improvement rate for liver elastography depending on ALT activity prior to antiviral therapy.

\section{Discussion}

In the past two decades, a lot of work has been carried out throughout the world to reduce the incidence of HCV infection in the HD population, but the issue still persists, especially in countries with low levels of socio-economic development. Given the significance of HCV prognosis in HD patients, the elimination of the virus is an important factor, significantly improving RRT results. The new GLE/PIB combination has demonstrated its high efficacy in the treatment of all HCV genotypes and has no contraindications in patients suffering from severe renal dysfunction. At the same time, not much experience has been gained in using these drugs in HD patients. Our group of 16 patients presented mainly with the genotype 3 virus. Among four patients with genotype 2 , one had a rather rare recombinant strain $(2 \mathrm{k} / 1 \mathrm{~b})$. After four weeks of treatment, the virus was eradicated in almost all patients. Only in one case (patient with liver cirrhosis) did this happen after 8 weeks of treatment. SVR12 and SVR24 were achieved in all patients, including the patient with the $2 \mathrm{k} / 1 \mathrm{~b}$ virus.

The high efficacy of the 12-week GLE/PIB course in patients with severe renal dysfunction, $82 \%$ of whom received HD treatment, was also reported by Gane E et al. [14]. With all HCV genotypes, their group was dominated by genotypes 1 and 4 . The SVR rate was $98 \%$. Similar results but with infection with genotypes 2 and 3 were achieved in the Japanese population, [15-17]. The SVR in these reports was $96.3 \%, 98.9 \%$ and $99.3 \%$. In three other Japanese studies, HD patients with genotypes 1 and 2 were treated with this combination for 8 or 12 weeks, with the duration of the treatment determined by the cirrhosis status. According to Kumada H et al. [18] and Hotta N [19], SVR12 was $100 \%$ as was in our HD patients' group, while Tanaka Y [20] reported a SVR12 rate of $94.4 \%$. There is a lack of data related to $\mathrm{HCV}$ treatment in $2 \mathrm{k} / 1 \mathrm{~b}$-infected patients, especially with modern DAA therapy. This type was first detected in blood samples of chronic HCV patients in Saint-Petersburg (Russia) in the early 21 st century $[21,22]$. Its detection rate was $7.5 \%$ of the total number of infected individuals and $6.3 \%$ of HD patients diagnosed with HCV in this city [23].

In Russia in general, the recombinant $2 \mathrm{k} / 1 \mathrm{~b}$ variant accounted for $4 \%$ of the total number of $\mathrm{CHC}$ cases and $40 \%$ of patients diagnosed with genotype 2 [24]. A group of German researchers also noted a high rate of $2 \mathrm{k} / 1 \mathrm{~b}$ diagnoses among patients infected with genotype 2 in Germany (13\%) and especially in Israel (25\%) - probably as result of the large-scale immigration from former Soviet republics. Conversely, the $2 \mathrm{k} / 1 \mathrm{~b}$ variant is rare in Italy, with a smaller number of such migrants [25]. In view of the high prevalence of the recombinant genotype $2 \mathrm{k} / 1 \mathrm{~b}$ in Russia, it is common practice to perform a more detailed HCV geno-/subtype sequencing analysis in genotype 2 individuals. This resulted in the detection of the $2 \mathrm{k} / 1 \mathrm{~b}$ variant in one of our patients.

It has been established that the combination of Sofosbuvir/ Ribavirin previously used in genotypes 2 and 3 has proven to be less effective in the case of this chimeric type [25]. Pangenotypic DAAs (Sofosbuvir/Daclatasvir, Sofosbuvir/Velpatasvir) and combinations recommended for the treatment of HCV genotype 1 (Sofosbuvir/Ledipasvir and the so-called"3D-therapy") were effective in patients diagnosed with $2 \mathrm{k} / 1 \mathrm{~b}$, both as a primary treatment $(\mathrm{n}=9)$ or following an unsuccessful SOF/RBV treatment $(\mathrm{n}=13)$. The SVR12 rate was registered at 95.5\% [25]. As SOF administration was not possible in our $2 \mathrm{k} / 1 \mathrm{~b}$ patient due to the low glomerular filtration rate, we opted to use the pangenotypic GLE/PIB combination. This was the first experience of using GLE/ $\mathrm{PIB}$ in a $2 \mathrm{k} / 1 \mathrm{~b}$ patient suffering from severe renal dysfunction [26]. 
Typically, ALT values in our patients were not too high. Many authors reported significantly reduced liver enzyme activity in HD patients compared to persons with normal renal function, attributing this to various reasons $[27,28]$.

In 14 out of 16 patients, repeated liver TE was performed at different periods after the DAAs therapy. Almost all patients showed improvement, and in 5 out of 14 (36\%) a decrease in the index of liver stiffness even corresponded to a decrease in the stage of fibrosis by 1 or more gradations. It should be emphasized that the improvement of TE indicators occured more often in patients with initially elevated levels of ALT activity. This suggests that an increase in the elasticity of the liver parenchyma after treatment may be caused by a decrease in inflammatory activity, rather more than a decrease in the degree of fibrosis.

We observed that HD patients demonstrated good GLE/PIB therapy tolerance. Adverse effects in our group were only skinrelated (itching) in a small proportion of patients, which is fully consistent with the data provided by Hotta N \& Tanaka Y et al. $[19,20]$. There were no cases of the early termination of the antiviral therapy.

\section{Conclusion}

So, the GLE/PIB combination proved to be highly effective and safe in HD patients with HCV genotypes 2 and 3, including the $2 \mathrm{k} / 1 \mathrm{~b}$ chimeric variant. The treatment results achieved for HD patients infected with these virus genotypes pave the way for the complete elimination of the HCV infection. The possibility of liver fibrosis reversibility in hemodialysis patients following effective antiviral treatment calls for further studies with larger patient groups and a longer follow-up period.

\section{Conflict of Interest}

Zubkin ML is a lecturer at AbbVie, Bristol-Myers Squibb, MSD, and Gilead Sciences. Other authors do not have a conflict of interest.

\section{References}

1. Zignego AL, Ramos-Casals M, Ferri C, Saadoun D, Arcaini L, et al (2017) International therapeutic guidelines for patients with HCVrelated extrahepatic disorders. A multidisciplinary expert statement. Autoimmun Rev 16(5): 523-541.

2. Ferri C, Ramos-Casals M, Zignego AL, Arcaini L, Roccatello D, et al. (2016) International diagnostic guidelines for patients with HCVrelated extrahepatic manifestations. A multidisciplinary expert statement. Autoimmun Rev 15(12): 1145-1160.

3. Furusyo N, Hayashi J, Ariyama I, Sawayama Y, Etoh Y, et al. (2000) Maintenance hemodialysis decreases serum hepatitis C virus (HCV) RNA levels in hemodialysis patients with chronic HCV infection. Am J Gastroenterol 95(2): 490-496.

4. Ishida H, Agishi T, Koyama I, Sawada T, Murakami T, et al. (2001) The hemodialysis paradox: survey on the incidence rate of hepatocellular carcinoma in antihepatitis virus C-antibody-positive chronic hemodialysis patients. Artif Organs 25(1): 58-60.
5. Aslinia FM, Wasan SK, Mindikoglu AL, Adeyemo OA, Philosophe B, et al. (2012) End-stage renal disease and the African American race are independent predictors of mild liver fibrosis in patients with chronic hepatitis C infection. J Viral Hepat 19(5): 371-376.

6. Baid-Agrawal S, Pascual M, Moradpour D, Somasundaram R, Muche M, et al. (2014) Hepatitis C virus infection and kidney transplantation in 2014: what is new? Am J Transplant 14(10): 2206-2220.

7. Fabrizi F, Martin P, Dixit V, Bunnapradist S, Dulai G (2005) Hepatitis C virus antibody status and survival after renal transplantation: metaanalysis of observational studies. Am J Transplant 5(6): 1452-1461.

8. Kidney Disease: Improving Global Outcomes (KDIGO) (2008) KDIGO clinical practice guidelines for the prevention, diagnosis, evaluation, and treatment of hepatitis C in chronic kidney disease. Kidney Int 109: 1-99.

9. Toyoda H, Kumada T, Tada T, Takaguchi K, Ishikawa T, et al. (2016) Safety and efficacy of dual direct-acting antiviral therapy (daclatasvir and asunaprevir) for chronic hepatitis $C$ virus genotype 1 infection in patients on hemodialysis. J Gastroenterol 51(7): 741-747.

10. Roth D, Nelson DR, Bruchfeld A, Liapakis A, Silva M, et al. (2015) Grazoprevir plus elbasvir in treatment-naive and treatmentexperienced patients with hepatitis $C$ virus genotype 1 infection and stage $4-5$ chronic kidney disease (the C-SURFER study): a combination phase 3 study. Lancet 386(10003): 1537-1545.

11. Pockros PJ, Reddy KR, Mantry PS, Cohen E, Bennett M, et al. (2016) Efficacy of direct-acting antiviral combination for patients with the Hepatitis $C$ virus genotype 1 infection and severe renal impairment or end-stage renal disease. Gastroenterology 150(7): 1590-1598.

12. Ponziani FR, Siciliano M, Lionetti R, Pasquazzi C, Gianserra L, et al (2017) Effectiveness of Paritaprevir/Ritonavir/Ombitasvir/Dasabuvir in hemodialysis patients with the hepatitis $C$ virus infection and advanced liver fibrosis: Case Reports. Am J Kidney Dis 70(2): 297-300.

13. Ledinghen V De, Vergniol J (2008) Transient elastography (FibroScan). Gastroenterologie Clin Bio 32: 58-67.

14. Gane E, Lawitz E, Pugatch D, Georgios Papatheodoridis, Norbert Bräu, et al. (2017) Glecaprevir and pibrentasvir in patients with HCV and severe renal impairment. N Engl J Med 377(15): 1448-1455.

15. Suda G, Hasebe C, Abe M, Kurosaki M, Itakura J, et al. (2019) Safety and efficacy of glecaprevir and pibrentasvir in Japanese hemodialysis patients with genotype 2 hepatitis C virus infection. J Gastroenterol 54(7): 641-649.

16. Ogawa E, Furusyo N, Nakamuta M, Nomura H, Satoh T, et al. (2019) Glecaprevir and pibrentasvir for Japanese patients with chronic hepatitis C genotype 1 or 2 infection: Results from a multicenter, realworld cohort study. Hepatol Res 49(6): 617-626.

17. Atsukawa M, Tsubota A, Toyoda H, Takaguchi K, Nakamuta M, et al. (2019) The efficacy and safety of glecaprevir plus pibrentasvir in 141 patients with severe renal impairment: a prospective, multicenter study. Aliment Pharmacol Ther 49(9): 1230-1241.

18. Kumada H. Watanabe T, Suzuki F, Keda K, Sato K, et al. (2018) Efficacy and safety of Glecaprevir/Pibrentasvir in HCV-infected Japanese patients with prior DAA experience, severe renal impairment, or genotype 3 infection. J Gastroenterol 53(4): 566-575.

19. Hotta N (2019) Efficacy and safety of Glecaprevir/Pibrentasvir in combination therapy in chronic hemodialysis patients with genotype 2 hepatitis $C$ virus infection. Open J Gastroenterol 9: 1-6.

20. Tanaka Y, Masaki T, Uojima H, Ohtake T, Fujikawa T, et al. (2018) Glecaprevir and pibrentasvir combination therapy for hepatitis C virus-infected Japanese patients on hemodialysis. Renal Replacement Therapy 4(51): 2-7. 
21. Kalinina O, Norder H, Mukomolov S, Magnius LO (2002) A natural intergenotypic recombinant of hepatitis $\mathrm{C}$ virus identified in St. Petersburg. J Virol 76(8): 4034-4043.

22. Raghwani J, Thomas XV, Koekkoek SM, Schinkel J, Molenkamp R, et al. (2012) Origin and evolution of the unique hepatitis $C$ virus circulating recombinant form 2k/1b. J Virol 86(4): 2212-2220.

23. Kalinina O (2012) Genome organization and geographical distribution of the natural intergenotypic recombinant of hepatitis $\mathrm{C}$ virus RF1_2k/1b. Infekc immun 4: 677-686.

24. Karandashova IV, Bulatova KV, Chulanov VP (2017) Prevalence of the recombinant form RF1_2k/1b of hepatitis C virus in Russia. Molecular diagnostics 1: 56-57.

25. Susser S, Dietz J, Schlevogt B, Zuckerman E, Barak M, et al. (2017) Origin, prevalence and response to therapy of hepatitis $C$ virus genotype 2k/1b chimeras. J Hepatol 67(4): 680-686.
26. Zubkin ML, Shchepetkova GS, Balkarova OV, Chervinko VI, Kryukov EV, et al. (2019) Successful Hepatitis C Virus Eradication in a Hemodialysis Patient With 2k/1b Chimera Genotype: A Case Report and Literature Review. Gastroenterology Res 12(3): 176-180.

27. Espinosa M, Martin-Malo A, Alvarez de Lara MA, Soriano S, Aljama P, et al. (2000) High ALT levels predict viremia in anti-HCV-positive HD patients if a modified normal range of ALT is applied. Clin Nephrol 54(2): 151-156.

28. Guh JY, Lai Y, Yang CY, Chen SC, Chuang WL, et al. (1995) Impact of decreased serum transaminase levels on the evaluation of viral hepatitis in hemodialysis patients. Nephron 69(4): 459-465.

\section{Your next submission with JuniperPublishers will reach you the below assets}

- Quality Editorial service

- Swift Peer Review

- Reprints availability

- E-prints Service

- Manuscript Podcast for convenient understanding

- Global attainment for your research

- Manuscript accessibility in different formats

( Pdf, E-pub, Full Text, audio)

- Unceasing customer service

Track the below URL for one-step submission https://juniperpublishers.com/online-submission.php 